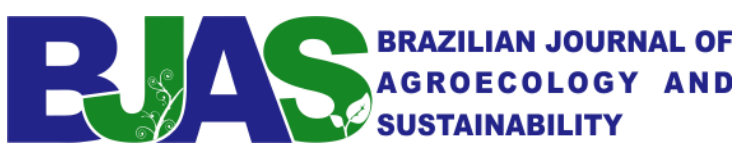

SUSTAINABILITY

Recebido: 09-07-2020 | Revisado: 11-09-2020 | Aceito: 30-12-2020

ARTIGO

\title{
Iniciativas colectivas de consumo ecolóxico en Galicia: panorama actual, modelos e acción socioeducativa
}

\section{Collective initiatives of ecological consumption in Galicia: current panorama, models and socio-educational action}

\section{Kylyan Marc Bisquert i Pérez e Pablo Ángel Meira Cartea ${ }^{1}$}

DOI: https://doi.org/10.52719/bjas.v2i2.3709

\section{RESUMO}

As iniciativas colectivas de consumo ecolóxico teñen unha presencia relativamente arraigada e, ata certo punto, consolidada en Galicia. Estas poden constituír unha avanzada sociocultural alternativa e actuar como axentes socioeducativos para promover entre a cidadanía a adopción de dietas sustentables que acompasen a configuración de sistemas agroalimentarios acordes que as abastezan, contribuíndo deste xeito ao desenvolvemento e difusión da cultura da sustentabilidade a través do consumo como ámbito de acción colectiva. Mediante un deseño de estudo de casos múltiple, neste traballo preséntanse os resultados dunha análise descritiva dun conxunto de 37 iniciativas colectivas de consumo ecolóxico presentes actualmente en Galicia, ofrecendo unha clasificación por tipos e modelos, a súa distribución territorial e a evolución e cambio de modelo nalgúns casos salientables, así como algunhas das súas características principais, como a súa antigüidade, figura xurídica, motivacións de orixe, composición, grao de implicación das persoas que as compoñen e aspectos referidos á loxística de distribución e os espazos empregados para tal efecto ou á gobernanza. Por último, achéganse unhas liñas xerais da dimensión socioeducativa das iniciativas estudadas, destacando as principais actividades desenvolvidas, os temas máis recorrentes, os obxectivos prioritarios e as dificultades que as iniciativas enfrontan á hora de desenvolver esta dimensión da súa acción colectiva. En resumo, preténdese achegar unha panorámica actual do estado xeral do consumo ecolóxico colectivo en Galicia, así como un esbozo do potencial socioeducativo deste tipo de iniciativas á hora de difundir e facer extensivo ao conxunto da cidadanía os valores e prácticas asociados á Agroecoloxía.

\footnotetext{
${ }^{1}$ Grupo de Investigación en Pedagoxía Social e Educación Ambiental SEPA-interea Universidade de Santiago de Compostela
} 
Palabras clave: Iniciativas colectivas. Consumo ecolóxico. Dimensión socioeducativa. Agroecoloxía. Cultura da sustentabilidade.

\begin{abstract}
Collective initiatives of ecological consumption have a relatively rooted and consolidated presence in Galicia. These can constitute an advanced sociocultural alternative and act as socioeducational agents to promote among citizens the adoption of sustainable diets that accompany the configuration of according agri-food systems that supply these, thus contributing to the development and dissemination of the culture of sustainability through consumption as a field of collective action. Using a multiple case study design, this paper presents the results of a descriptive analysis of a set of 37 collective initiatives of ecological consumption currently present in Galicia, offering a classification by types and models, their territorial distribution and the evolution and change of model in some notable cases, as well as some of their main characteristics, such as their oldness, legal status, original motivations, composition, degree of involvement of the people who make them up and aspects related to distribution logistics, the spaces used for this purpose or the governance. Finally, general outlines of the socioeducational dimension of the initiatives studied are provided, highlighting the main activities developed, the most recurring themes, the priority objectives and the difficulties that the initiatives face when developing this dimension of their collective action. In short, it is intended providing a current overview of the state of collective ecological consumption in Galicia, as well as a first approach to the socio-educational potential of this kind of initiatives when it comes to disseminating and extending to all citizens the values and practices associated with
\end{abstract} Agroecology.

Keywords: Collective initiatives. Ecological consumption. Socio-educational dimension. Agroecology. Culture of sustainability.

\title{
1 INTRODUCIÓN
}

Segundo o último barómetro sobre a percepción e o consumo de alimentos ecolóxicos en Galicia (Consello Regulador de Agricultura Ecolóxic de Galicia [CRAEGA], 2017), o consumo ecolóxico experimentou un aumento xeral entre a poboación galega, situándose no 47,3\% en 


\section{BRAZILIAN JOURNAL OF \\ AGROECOLOGY AND \\ SUSTAINABILITY}

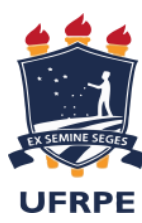

$2017^{2}$. Así mesmo, rexistrouse tamén un aumento xeral nas frecuencias de consumo de alimentos ecolóxicos, especialmente entre quen os consumía ocasionalmente. Porén, o supermercado segue a ser a canle principal de comercialización, cunha cota do 88,9\% no consumo en xeral e dun 43,2\% no do produto ecolóxico. Entre as motivacións rexistradas para consumir alimentos ecolóxicos predominan as de carácter individualista - saúde, sabor ou calidade do produto-, mentres que as que teñen unha compoñente de compromiso cidadá ou ideolóxico - criterios ambientais ou conviccións e ideas persoais - son ás menos recorrentes.

Con todo, estudos recentes sinalan que Galicia é a segunda comunidade autónoma do Estado español - só por detrás de Asturias - coa maior pegada de carbono asociada á dieta (Esteve-Llorens et al., 2020), principalmente debido á substitución dos estándares tradicionais da dieta atlántica polos modelos hexemónicos da dieta occidental, máis rica en produtos de procedencia animal e que incorpora alimentos industrialmente procesados (Esteve-Llorens, Moreira, Feijoo, \& González-García, 2019). Se ben estes estudos non inclúen o modelo de produción nin o transporte de alimentos entre as variables analizadas, faise patente a necesidade de promover a adopción de dietas sustentables, que ademais de incluír criterios nutricionais, ambientais, ético-políticos, culturais e socioeconómicos, deben acompasar a configuración de sistemas agroalimentarios acordes que as abastezan (Meybeck \& Gitz, 2017).

Neste sentido, as iniciativas colectivas de consumo ecolóxico ${ }^{3}$ (ICCE en adiante) poden constituír "exemplificantes espazos de innovación comunitaria nos que a cidadanía se convirte en axente educador" (Lema-Blanco, García-Mira, \& Muñoz-Cantero, 2015, p. 32), creando marcos socioculturais alternativos, achegando novas ferramentas sociais e aprendizaxes individuais e colectivas, e ensaiando novas formas de gobernanza e dinámicas de empoderamento cidadán, autoeficacia e desenvolvemento de novas capacidades. Ou mesmo, como sinalan Couceiro et al. (2016), difundindo e xeneralizando modelos alternativos de produción e consumo, constituíndo unha avanzada sociocultural e actuando como axentes promotores dunha cultura agroalimentaria alternativa. É dicir, impulsando o desenvolvemento da cultura da sustentabilidade (Herrero, Cembranos, \& Pascual, 2011) a través do consumo como ámbito de acción colectiva. Correspóndense coas iniciativas de consumo ecolóxico e

\footnotetext{
${ }^{2}$ Neste barómetro considérase consumidor ecolóxico "aquel individuo cunha frecuencia de consumo de alimentos ecolóxicos superior ou igual a unha vez ao mes" (CRAEGA, 2017, p.17).

${ }^{3}$ Adoptamos esta denominación dado que o trazo común das iniciativas aquí analizadas é o consumo de produtos ecolóxicos -sexan ou non certificados e considerados baixo distintos criterios-, aínda que hai moitas outras posibles, tal como se reflexiona no seguinte artigo de opinión da revista Opcións: http://opcions.org/es/opinion/consumo-consciente/ [Revisado o 7 de maio de 2020].
} 

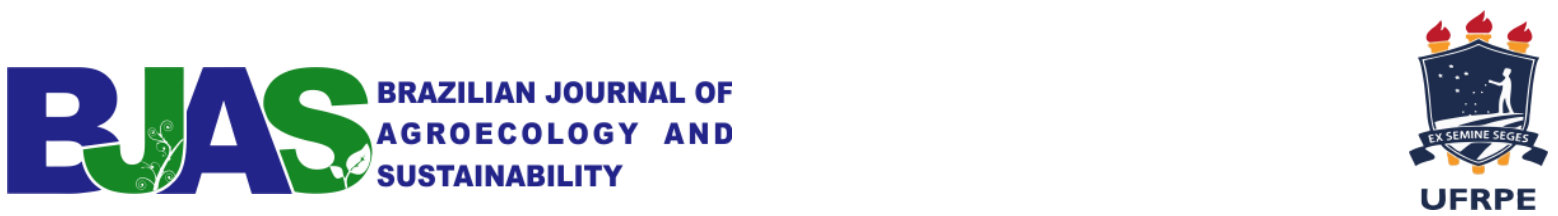

responsable de alimentos caracterizadas, inventariadas e clasificadas por Simón, Copena e Rodríguez (2010). Sen embargo, neste traballo optouse por outra clasificación, identificando a través dunha estratexia de categorización indutiva -sempre imperfecta e matizable dado que cada caso ten as súas particularidades - tipos ou modelos concretos presentes actualmente no territorio galego: grupos de consumo, cooperativas de consumo, redes de produción e consumo, iniciativas de comercialización e mercados autoxestionados.

As ICCE teñen unha presencia relativamente arraigada e, ata certo punto, consolidada en Galicia. Actualmente dispoñemos de múltiples referencias a experiencias e modelos presentes neste territorio en distintos estudos (Simón et al., 2010; Rodríguez, 2014; Soares et al., 2020), así como en guías ${ }^{4}$, cartografías dixitais ${ }^{5}$ ou medios de comunicación ${ }^{6}$. Resulta relevante destacar as iniciativas que conformaban a extinta Rede Galega de Consumo Consciente e Sostíbel $^{7}$, estudadas por Lema-Blanco et al. (2015). Porén, a día de hoxe non hai un rexistro actualizado e exhaustivo destas iniciativas a nivel galego, e menos aínda unha análise detallada das súas características principais. Así mesmo, alén da aproximación realizada por Lema-Blanco et al. (2015), tampouco se ten explorado en profundidade a súa dimensión socioeducativa, co fin de valorar ata que punto poden estar a desempeñar unha función relevante no impulso de dietas e sistemas agroalimentarios sustentables nas comunidades nas que se insiren.

\section{MÉTODO}

No marco dunha investigación de tese de doutoramento sobre o movemento agroecolóxico en Galicia, desenvolveuse un deseño de estudo de casos múltiples mediante a aplicación de entrevistas semi-estruturadas a persoas informantes, integrantes de iniciativas colectivas localizadas en Galicia. Para tal efecto, deseñouse un instrumento de recollida de

\footnotetext{
${ }^{4}$ Como exemplo, o Directorio de Alimentación Ecolóxica Galega recentemente publicado por Amigos da Terra (marzo de 2019), dispoñible en https://amigosdaterra.net/info/160415_adt/2019/03/25/amigos-da-terra-presentaun-directorio-de-alimentacion-ecoloxica/ [Revisado o 7 de maio do 2020].

${ }^{5}$ Ver, por exemplo, http://rizomas.info [Revisado o 20 maio do 2020].

${ }^{6}$ Ver, por exemplo, a reportaxe publicada en 2017 en El Salto: https://www.elsaltodiario.com/economiasocial/consumo-para-a-xente [Revisado o 20 de maio do 2020].

${ }^{7}$ Segundo Lema-Blanco et al. (2015), esta rede estaba conformada por "unha vintena de asociacións ou cooperativas presentes nas principais cidades do territorio galego (A Coruña, Santiago, Pontevedra, Vigo, Lugo, Ourense, Ferrol) e poboacións medianas (Allariz, Redondela, Lalín, Cervo, Ribadeo)" (p. 31) e que, de xeito autónomo, constituíanse "co obxecto de fomentar hábitos de consumo sostibles, desenvolver actividades educativas e participar en accións de transformación social" (p. 31). A nivel global, esta rede agrupaba "arredor de 1.500 socios ("unidades familiares") e [traballaba] en colaboración con pequenos produtores locais de agricultura ecolóxica e distribuidores de produtos de comercio xusto" (p. 31).
} 


\section{RAS \\ SUSTAINABILITY}

UFRPE

datos - un guión de entrevista estandarizado- validado a través do método do xuízo de expertos (Bisquert \& Meira, 2019). Alén das iniciativas aquí analizadas (n=37) (Táboa 1), esta investigación incluíu outros colectivos vinculados á agroecoloxía presentes na xeografía galega - un total de 46 -, atendendo aos seguintes criterios: función principal agroalimentaria, carácter colectivo, identidade agroecolóxica e autonomía con respecto a entidades públicas e privadas. Porén, para este traballo seleccionáronse unicamente os casos identificados como ICCE en calquera dos modelos anteriormente mencionados. Procurouse desenvolver unha mostraxe exhaustiva para saturar o universo de referencia. Sen embargo, alén das limitacións derivadas dunha investigación de tese, houbo iniciativas que rexeitaron participar, con outras non se conseguiu contactar ou (re)apareceron tras pechar o traballo de campo, e outras quedaron excluídas en función dos criterios establecidos, polo que é probable que se boten en falta aquí experiencias que tamén poderían ser consideradas ICCE.

Táboa 1: Lista de iniciativas analizadas.

\begin{tabular}{|c|l|c|c|}
\cline { 2 - 4 } \multicolumn{1}{l|}{} & Nome da iniciativa & Tipo & Localidade \\
\hline 1 & A Gradicela & Grupo de Consumo & Pontevedra \\
\hline 2 & A Landra & Grupo de Consumo & O Carballiño \\
\hline 3 & A Morangueira & Grupo de Consumo & Porto do Son \\
\hline 4 & Agrelar & Grupo de Consumo & Allariz \\
\hline 5 & Chulas e Bochos & Grupo de Consumo & Nigrán-Gondomar \\
\hline 6 & Des Pensa & Grupo de Consumo & Ponte Caldelas \\
\hline 7 & Eco_Lóxico & Grupo de Consumo & Ferrolterra \\
\hline 8 & Fonte da Uz & Grupo de Consumo & Culleredo \\
\hline 9 & GdC Orro & Grupo de Consumo & Vedra \\
\hline 10 & GdC Vedra & Grupo de Consumo & Oleiros \\
\hline 11 & Millo Miúdo & Grupo de Consumo & Ferreira de Pantón \\
\hline 12 & Muruxa & Grupo de Consumo & Verín \\
\hline 13 & O Grelo Verde & Grupo de Consumo & Antas de Ulla \\
\hline 14 & O Zuleiro & Grupo de Consumo & Cangas \\
\hline 15 & Paporrubios & Grupo de Consumo & Santiago de C. \\
\hline 16 & Proxecto Integral Compostela & Grupo de Consumo & Ourense \\
\hline 17 & Semente & Grupo de Consumo & Lalín \\
\hline 18 & Tarabela & Grupo de Consumo & Castro Caldelas \\
\hline 19 & Tarabelada & Grupo de Consumo & Carballo \\
\hline 20 & Xirimolo do Casino & Grupo de Consumo & Ourense \\
\hline 21 & Xurumelxs & Cooperativa de consumo & Vigo \\
\hline 22 & Aldea Integral & Cooperativa de consumo & Vigo \\
\hline 23 & Árbore & Cooperativa de consumo & Santiago de C. \\
\hline 24 & Panxea & Cooperativa de consumo & A Coruña \\
\hline 25 & Zocamiñoca & Rede de Produción e Consumo & Melide \\
\hline 26 & O Careón & Iniciativa de comercialización & Pontevedra \\
\hline 27 & Amarante Setem & Iniciativa de comercialización & Lugo \\
\hline 28 & Bico de Grao & Iniciativa de comercialización & Ferrol \\
\hline 29 & Mercado da Terra & & \\
\hline & & & \\
\hline
\end{tabular}




\begin{tabular}{|c|l|c|c|}
\hline 30 & Rexusto (Arquipélagos SCG) & Iniciativa de comercialización & Soutomaior \\
\hline 31 & 4 Ponlas & Mercado autoxestionado & Pontevedra \\
\hline 32 & Entre Lusco e Fusco & Mercado autoxestionado & Santiago de C. \\
\hline 33 & Foros Ecolóxicos da Barbanza & Mercado autoxestionado & Ribeira, Boiro e Rianxo \\
\hline 34 & Labrega Natura & Mercado autoxestionado & A Coruña \\
\hline 35 & Mercado da Terra & Mercado autoxestionado & Lugo \\
\hline 36 & Mercado de Alimento Labrego & Mercado autoxestionado & Teo \\
\hline 37 & O Toxo & Mercado autoxestionado & Gondomar \\
\hline
\end{tabular}

Elaboración propia.

\subsection{Iniciativas analizadas: modelos, distribución e evolucións}

Das 37 iniciativas analizadas, sobresaen en número os grupos de consumo (en adiante, GdC), con 21 casos. Como sinalan Couceiro et al. (2016), existe unha ampla diversidade de tipos de $\mathrm{GdC}$ en función de variables como o grao de implicación das participantes e de compromiso cos proxectos produtivos que os abastecen, a amplitude da variedade de produtos e provedores ou o tamaño do colectivo. Nos casos analizados apréciase dita pluralidade, incluíndo dende colectivos máis informais que organizan pedidos conxuntos puntuais, ata outros que basean parte do seu funcionamento no modelo de agricultura sostida pola comunidade $(\mathrm{ASC})^{8}$ - aínda que tamén fagan pedidos a outros provedores -, pasando por modelos máis clásicos de $\mathrm{GdC}$, que combinan a provisión regular de produtos frescos e de proximidade por parte de pequenas/os produtoras/es locais en ecolóxico - mais sen establecer o grao de compromiso propio da ASC - con pedidos puntuais ou periódicos a outros provedores externos - a nivel galego ou peninsular -, sexa a través dun funcionamento autoxestionado ou mediante a xestión profesionalizada por parte dunha persoa contratada para tal efecto (Figura $1)$.

\footnotetext{
${ }^{8}$ Para máis información sobre o modelo de ASC, recoméndase consultar o informe editado polo European CSA Research group e impulsado pola rede internacional de ASC Urgenci (European CSA Research Group, 2016).
} 

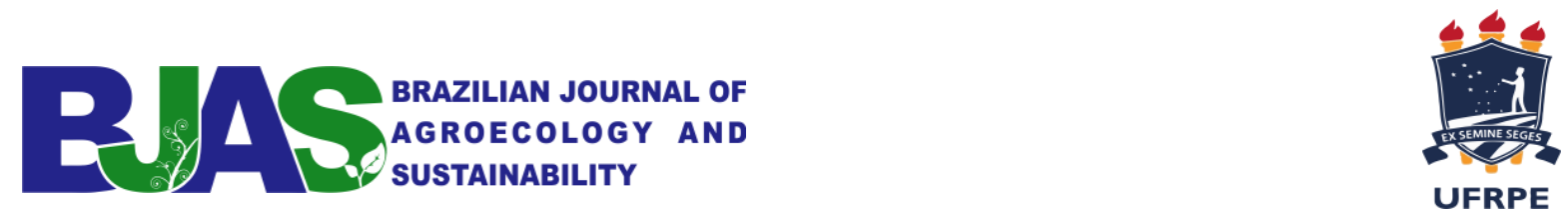

Figura 1. Espazos e procesos de reparto dos GdC.

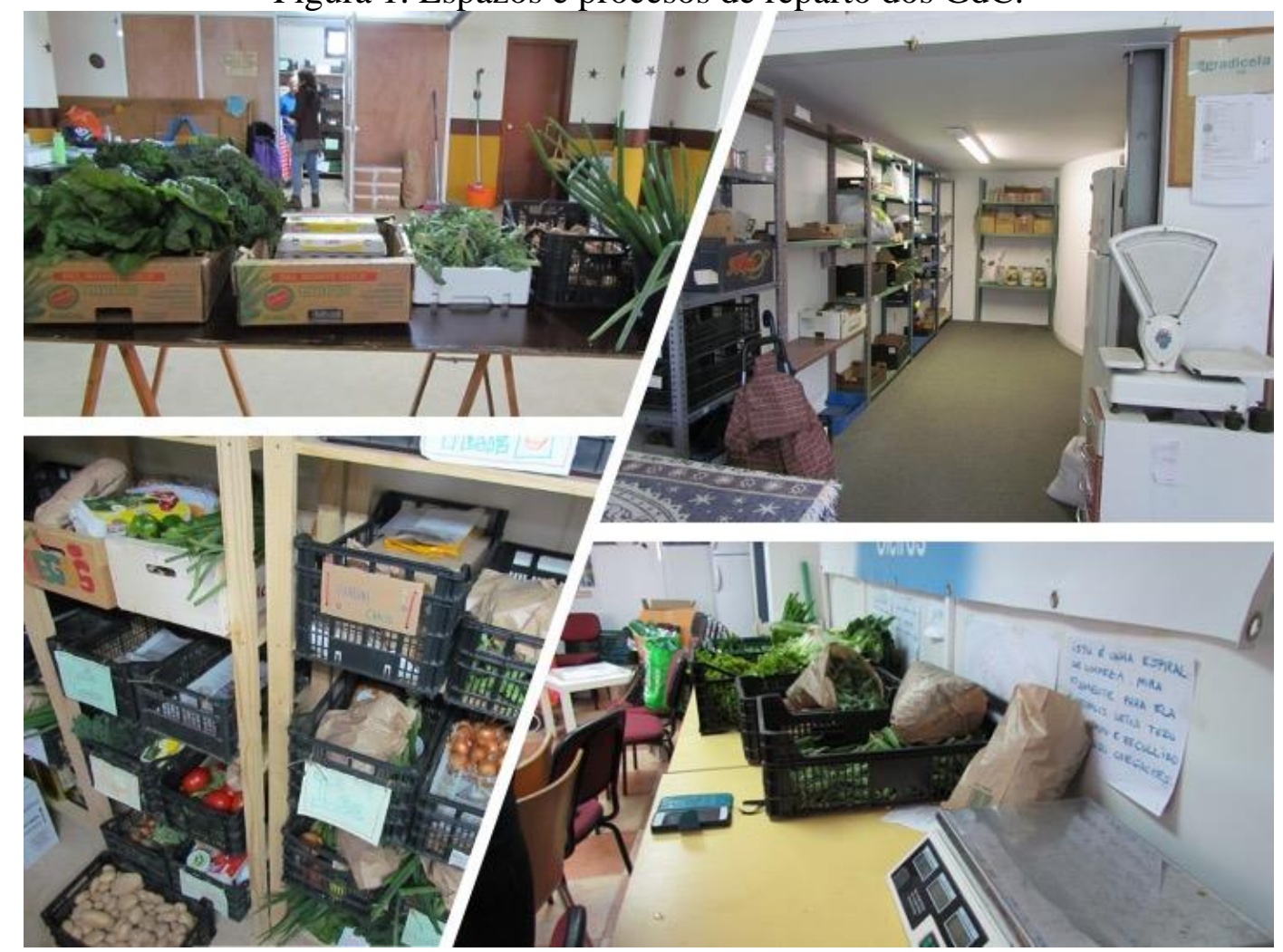

Esquerda: reparto no GdC Eco_Lóxico (Ponte Caldelas). Arriba-dereita: local do GdC A Gradicela (Pontevedra). Abaixo-dereita: reparto no GdC Millo Miúdo (Oleiros). Fotografías: K.M. Bisquert (2019).

A este tipo de colectivo, súmanse catro iniciativas cunha especial raizame e relevancia na dinamización doutras ICCE en Galicia, as cooperativas de consumo (Figura 2), así como unha rede de produción e consumo articulada a escala comarcal na Terra de Melide. Inclúense ademais catro casos que agrupamos como iniciativas de comercialización, sendo a categoría máis heteroxénea das aquí analizadas: Rexusto é un proxecto dunha cooperativa de traballo asociado (CTA) que xestiona a comercialización de alimentos de produtores locais para abastecer de cestas e pedidos complementarios a un conxunto de consumidores habituais, mais que entre si non conforman un GdC; Bico de Grao é unha CTA que xestiona unha tenda de alimentos ecolóxicos, aínda que tamén dispoñe de cestas pechadas de produto fresco para a recollida periódica no establecemento por consumidoras/es que asumen certo compromiso de regularidade e permanencia; o Mercado da Terra (Ferrol) é tamén unha CTA que xestiona unha tenda de produtos ecolóxicos, e que ademais é herdeira dunha das cooperativas de consumo históricas no contexto galego, A Xoaniña (Figura 2); por último, engádese tamén unha organización non gobernamental de desenvolvemento (ONG-D), Amarante Setem, que ten entre as súas liñas de acción distribuír e comercializar produtos de comercio xusto e ecolóxicos, e que ata hai aproximadamente un ano tamén xestionaba un GdC. Non se inclúen aquí, porén, 

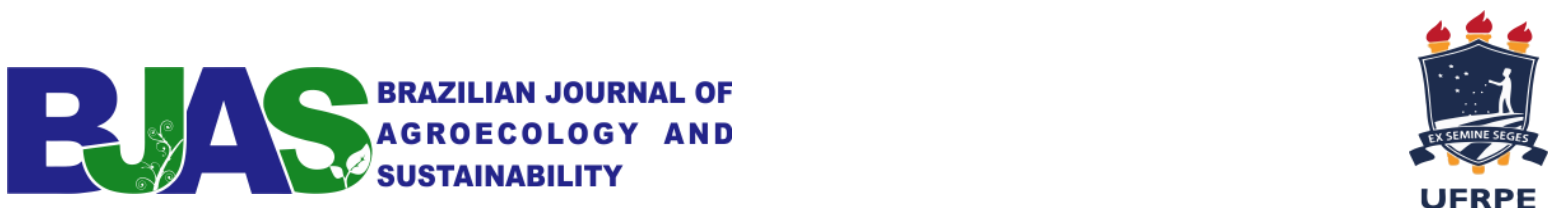

outras iniciativas estudadas que comercializan produtos ecolóxicos pero que non presentan ningunha das particularidades sinaladas nos casos analizados.

Figura 2. Locais de dous modelos de cooperativa.

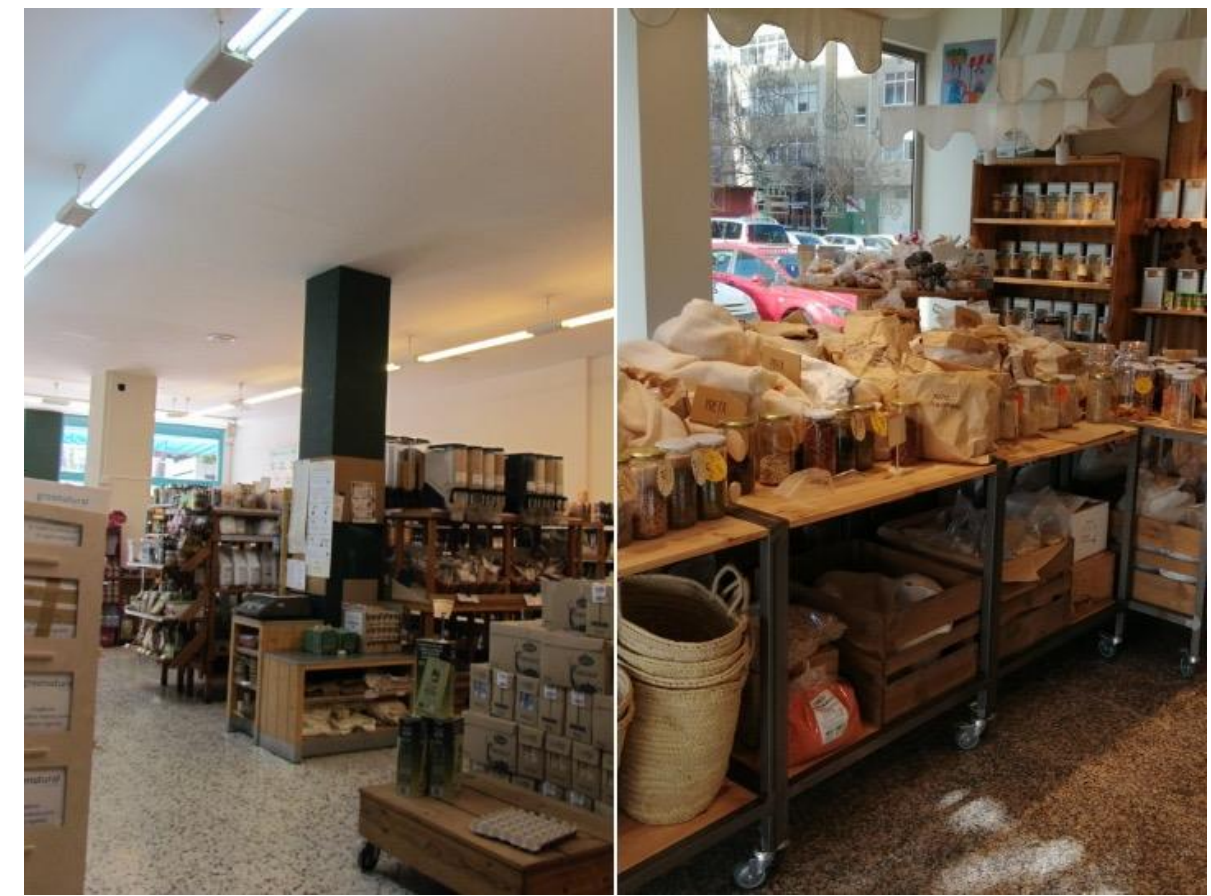

Esquerda: local da Cooperativa de Consumo Árbore (Vigo). Dereita: local da CTA Mercado da Terra (Ferrol). Fotografías: K.M. Bisquert (2019).

Por último, agréganse sete colectivos conformados por produtoras/es locais - e consumidoras/es nalgúns casos -, que organizan e celebran de maneira autoxestionada e periódica feiras, mercados e encontros de consumo responsable (Figura 3), ben sexa en prazas, parques e outros espazos ao aire libre, ben no interior de instalacións públicas municipais (Figura 7). 

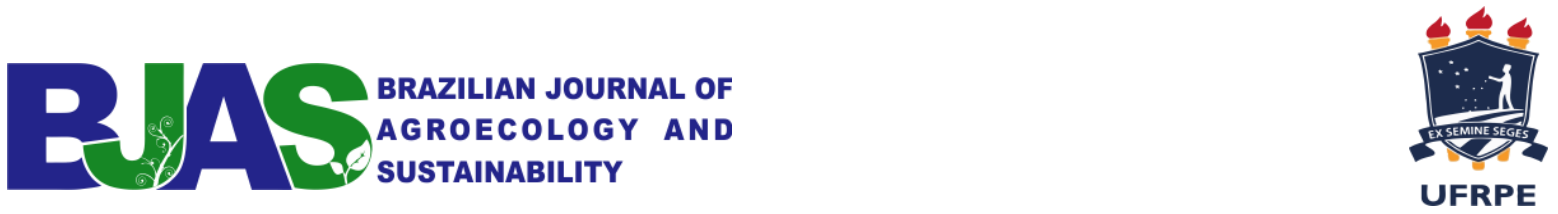

Figura 3. Feiras, mercados e encontros de consumo responsable.

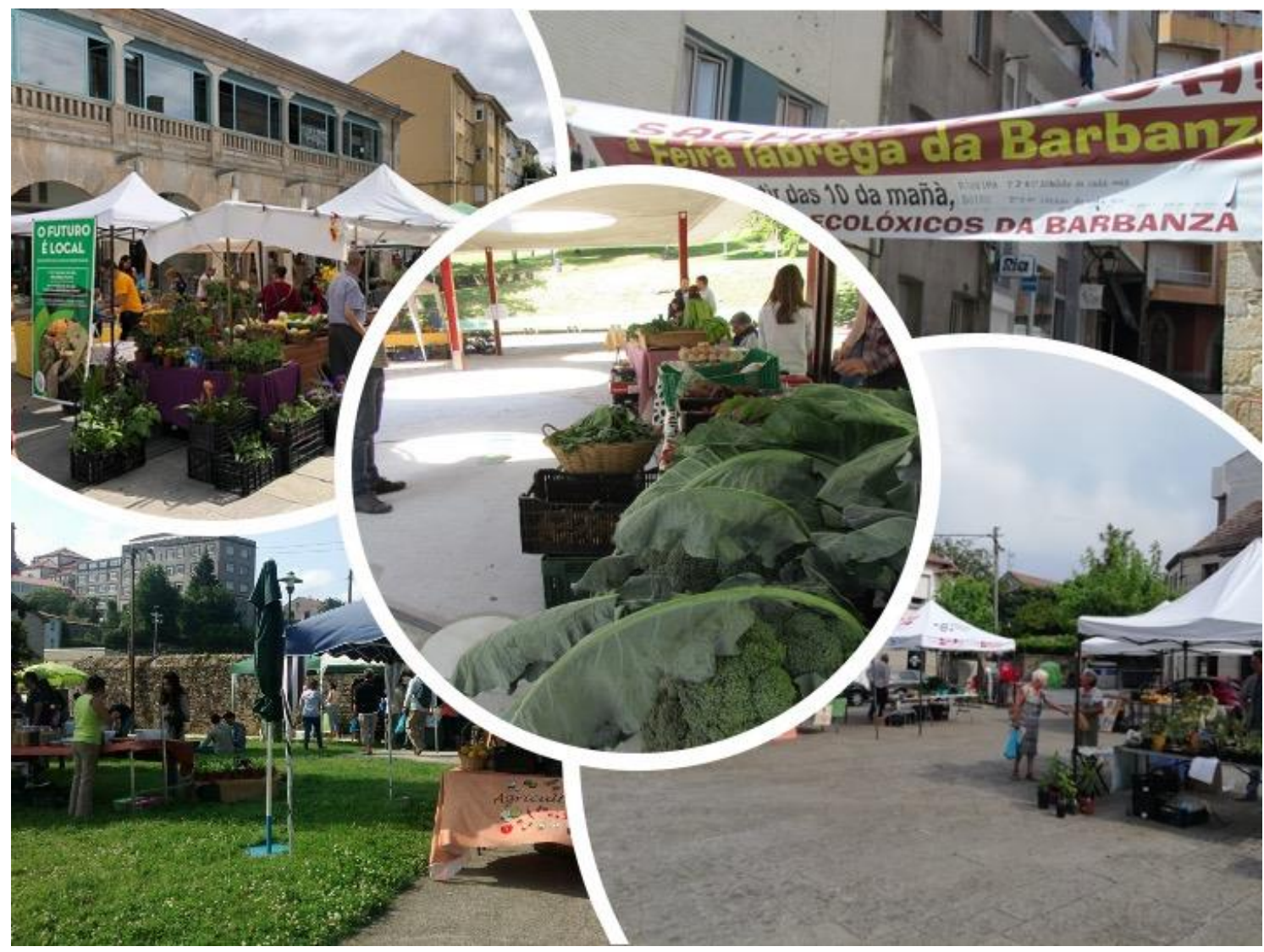

Arriba-esquerda: mercado 4Ponlas (Pontevedra); fotografía: https://www.facebook.com/4ponlas/ (2018). Arriba-dereita: faixa na feira labrega organizada polos Foros Ecolóxicos da Barbanza (Ribeira); fotografía: KM. Bisquert (2019). Abaixo-esquerda: mercado agroecolóxico Entre Lusco e Fusco (Santiago de Compostela); fotografía: https://www.facebook.com/mercadoentreluscoefusco (2018). Abaixo-dereita: encontro agroalimentario de produtoras e consumidoras organizado pola Asociación O Toxo (Gondomar); fotografía: https://www.facebook.com/asoc.otoxo (2019). Centro: Mercado de Alimento Labrego (Teo); fotografía: K.M. Bisquert (2019).

Con relación á distribución territorial das iniciativas analizadas (Figura 4), A Coruña é a provincia que aglutina un maior número (15), seguida por Pontevedra (12), Ourense (6) e Lugo (4). Rexistráronse iniciativas en dezanove comarcas da xeografía galega, sendo as que contan cun maior número as de Santiago e Vigo, ambas con cinco casos, seguidas das de A Coruña e Pontevedra, con catro casos cada unha. Outras catro comarcas rexistraron dous casos respectivamente: Ferrolterra, Lugo, Ourense e O Morrazo. Pódese apreciar unha maior concentración de iniciativas identificadas nas provincias atlánticas. Isto pode deberse tanto á maior densidade de poboación nesta rexión como ao feito de ser iniciativas que tradicionalmente tiveron carácter urbano, se ben tamén se desenvolven - e cada vez máis - en 

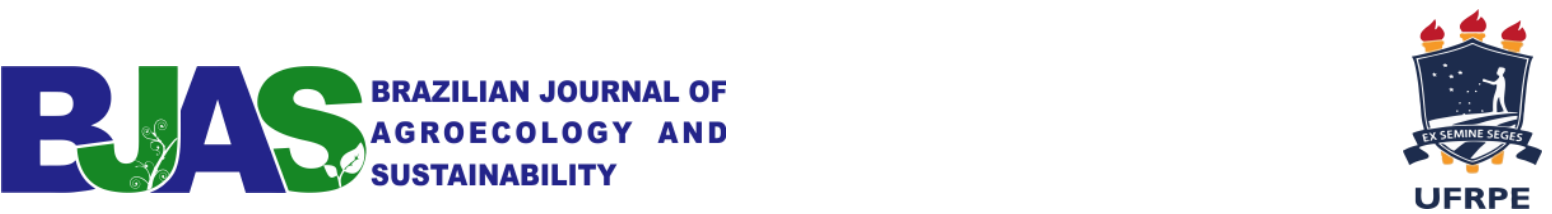

vilas máis pequenas e mesmo en contextos rurais ${ }^{9}$. De feito, hai casos cun dilatado percorrido histórico nestas contornas. Porén, cómpre ter en consideración neste sentido que, malia que as iniciativas estudadas tendan a concentrarse nas zonas máis densamente poboadas, as/os produtoras/es que as provén - ou mesmo que as promoven - presentan unha maior dispersión no territorio, desenvolvendo os seus proxectos produtivos en fincas situadas en áreas rurais, tanto das zonas costeiras como do interior, así como nas áreas periurbanas das áreas metropolitanas galegas (Figura 5). O seu grao de afastamento con respecto ás ICCE adoita ter un alcance comarcal ou provincial na maior parte dos casos - sobre todo entre as/os produtoras/es de horta e produto fresco en xeral -, e se ben nalgúns casos a procedencia das/dos produtoras/es pode ser máis ampla, sempre se restrinxe ao territorio galego.

Figura 4. Distribución territorial das iniciativas.

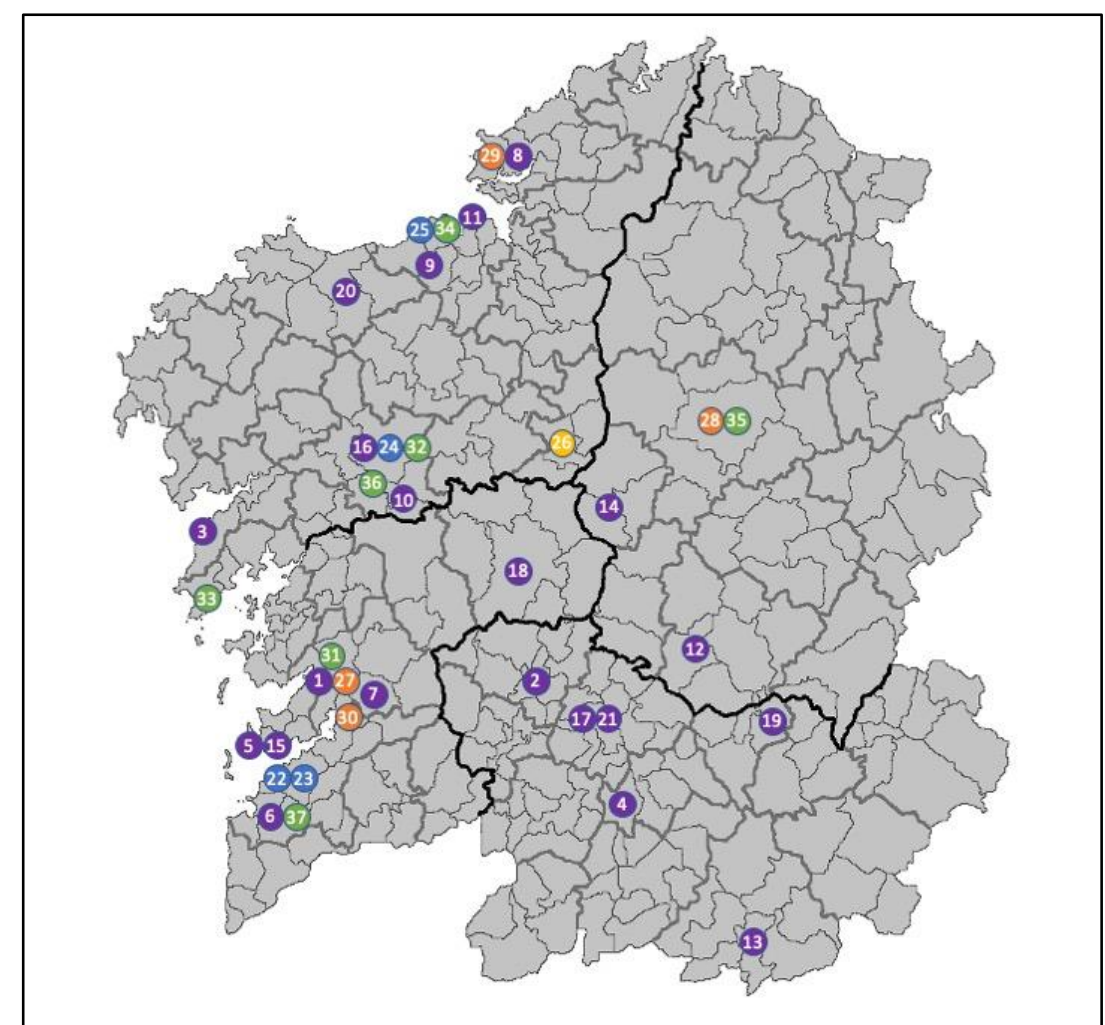

Elaboración propia (a numeración e a clasificación por cores correspóndese coas da lista da Táboa 1).

Figura 5. Fincas de produtoras/es que provén algunhas das iniciativas analizadas.

\footnotetext{
${ }^{9}$ En calquera caso, esta desequilibrada distribución territorial tamén pode atribuírse a un posible nesgo derivado da localización do investigador -Santiago de Compostela-, se ben se tratou de compensar esta posible tendencia procurando con especial énfase iniciativas nos territorios máis afastados
} 

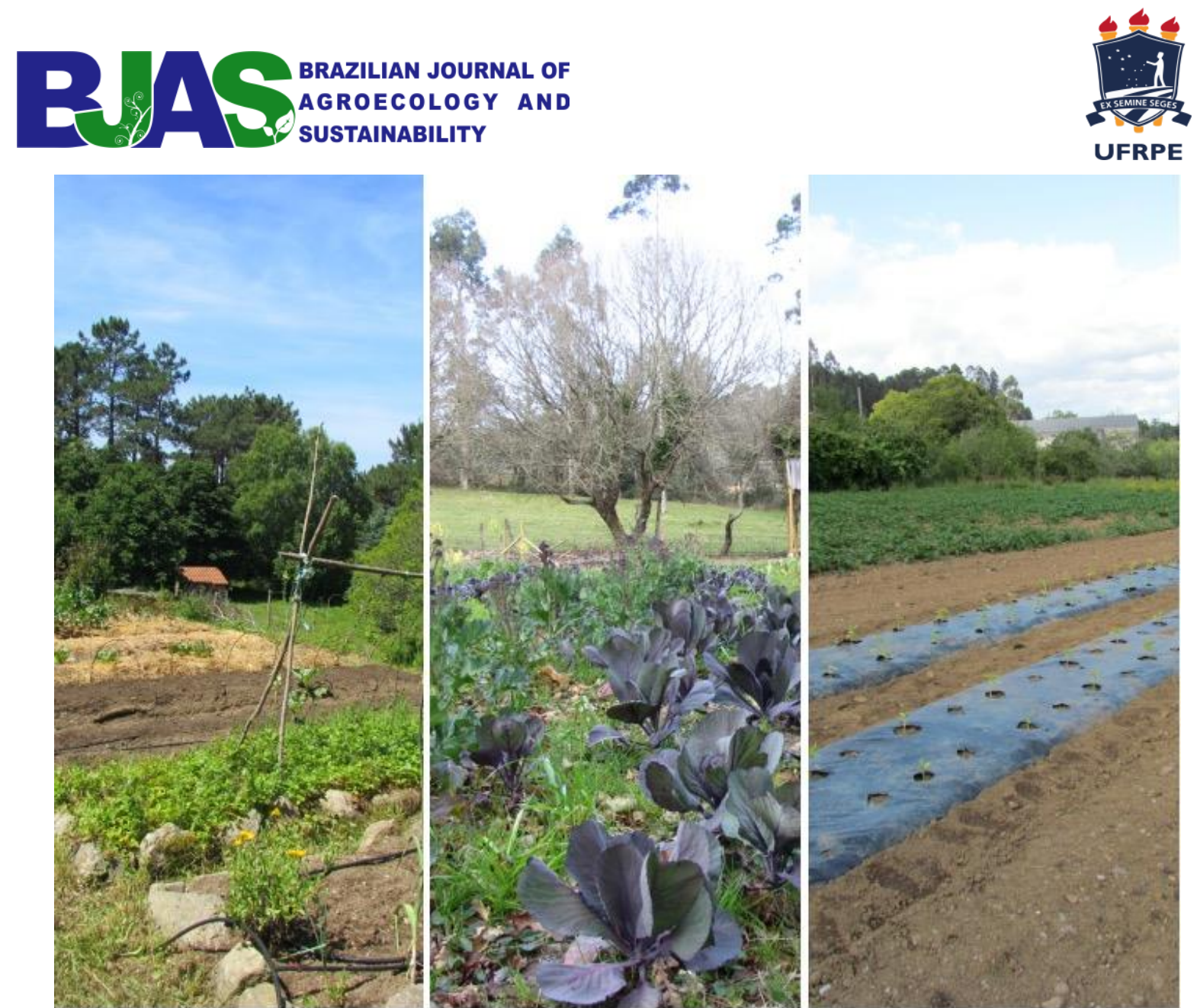

UFRPE

Exemplos de fincas de produtoras/es que proven iniciativas analizadas, situadas respectivamente en contextos rurais costeiros e do interior, ou en zonas rurais periurbanas de áreas metropolitanas. Esquerda: Xestas (Porto do Son). Centro: Roupar (Xermade). Dereita: Santa Marta de Babío (Bergondo).

Cómpre salientar a evolución experimentada nas iniciativas presentes nalgunhas zonas concretas, que deron lugar a modelos distintos, reproducíronse en novos colectivos ou foron mudando de modelo para adaptarse ás circunstancias das persoas que as integran.

No primeiro sentido, sobresae a Cooperativa de Consumo Eirado, fundada en Santiago de Compostela o ano 2008 e disolvida o 2014, non sen antes impulsar a creación en 2010 dos Encontros de Consumo Responsable Entre Lusco e Fusco, actualmente xestionados polas/os propias/os produtoras/es baixo o formato de «mercado agroecolóxico local». Ademais, algunhas persoas que formaban parte de Eirado organizaron posteriormente GdC máis informais, baseados na realización de pedidos puntuais a través de aplicacións dixitais de mensaxería instantánea, sendo hoxe do GdC de Vedra o máis estruturado, aínda que tamén hai certa actividade na capital galega. É similar o caso de Lugo, na que chegaron a coexistir a cooperativa de consumo pioneira en Galicia, A Cova da Terra -activa entre 1995 e 2017-, e a Asociación de Consumidores/as de Produtos Ecolóxicos e Artesanais O Bandullo Ecolóxico, 

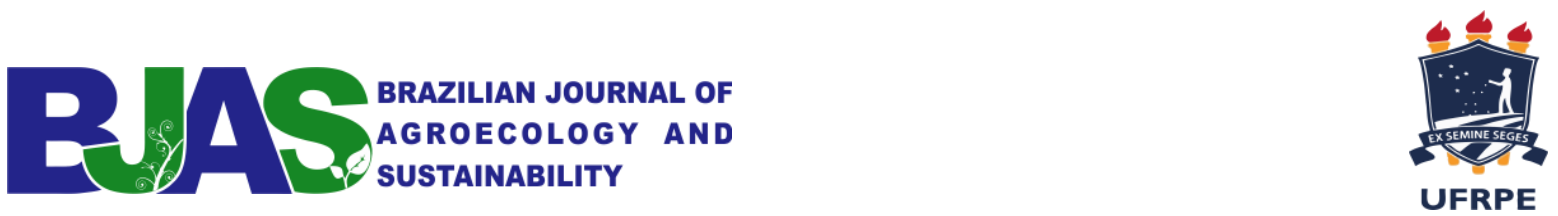

creada en 2002. Esta última, que contaba cunha tenda física e un sistema de cestas, sufriu un colapso debido ao seu propio crecemento e a discrepancias internas; tal como relata Vázquez (2017) - corroborado no traballo de campo -, os socios que permaneceron impulsaron en 2011 o Mercado da Terra como estratexia de reactivación. Esta nova iniciativa foi xestionada nun inicio polas/os consumidoras/es e produtoras/es participantes, tomando paulatinamente estas últimas maior protagonismo ata facerse cargo por completo. No Ferrol, antigas/os integrantes da Cooperativa de Consumo Responsable A Xoaniña, activa entre 2005 e 2014 cun gran número de socios, crearon en 2016 o GdC A Fonte da Uz, de menor dimensión e cunha estrutura menos complexa, se ben aínda cun volume de actividade considerable. Tras unha primeira etapa deste GdC, fundouse en 2019 a CTA de comercialización Mercado da Terra ${ }^{10}$, que xestiona unha tenda de produtos ecolóxicos. Así mesmo, A Fonte da Uz iniciou unha segunda etapa ese mesmo ano.

Cabe mencionar tamén o caso do noroeste da comarca de Vigo, onde dende 2009 tivo sede - concretamente en Redondela- a Asociación de Consumo Responsable Loaira, xa desaparecida. Sen embargo, no marco dunha CTA máis ampla - Arquipélago s-, un proxecto persoal de comercialización de alimentos ecolóxicos asentado en Soutomaior en 2014, Rexusto, dende 2019 está a coordinar a comercialización de produto de proximidade e pedidos a provedores externos para un conxunto de consumidores que, no entanto, non constitúen un GdC. Por outra banda, a vertente sur do Morrazo presenta actualmente unha particular proliferación de GdC, que en gran medida parte dun colectivo pioneiro conformado en Moaña en 2009, Patacas do Cedo, cuxo modelo se reproduciu no veciño concello de Cangas coa creación doutros dous GdC, Paporrubios en 2013 e Chulas e Bochos en 2017. En Ourense, debido ao excesivo crecemento do GdC Semente, creouse en 2013 un novo GdC, Xurumelxs, para dar cabida ás novas integrantes.

Por último, con máis de vinte anos de actividade na comarca de Verín, O Grelo Verde tivo unha evolución interna salientable, mantendo a entidade e o seu enfoque de promoción da agricultura ecolóxica e o desenvolvemento rural sostible, mais pasando de funcionar como un GdC durante toda a súa andaina a constituír nos últimos anos unha asociación esencialmente de produtores debido á actividade económica dos seus membros ${ }^{11}$.

\footnotetext{
${ }^{10}$ Neste caso trátase da SCG Mercado da Terra de Ferrol, non confundir co mercado autoxestionado de Lugo.

${ }^{11}$ Malia dita evolución, decidimos manter esta iniciativa na categoría de GdC -e tamén como ICCE- en virtude da súa traxectoria e de que aínda realizan pedidos puntuais.
} 


\section{PAG \\ AGROECOLOGY AND \\ SUSTAINABILITY}

\subsection{Características xerais das ICCE en Galicia}

En primeiro lugar, en canto á antiguiidade, a iniciativa máis lonxeva que mantén a súa actividade é a actual Cooperativa de Consumo Panxea, fundada en 1995 como asociación en Santiago de Compostela ${ }^{12}$. Esta foi seguida pola Asociación Cultural O Grelo Verde $-1997^{13}$. Posteriormente fundáronse a ONG-D Amarante Setem -1999- e a Cooperativa de Consumo Consciente Árbore -2001. Tras estas experiencias pioneiras, non foi ata a crise de 2008 que chegou unha nova vaga de iniciativas, que se mantivo con altibaixos nos anos posteriores. Por último, cómpre destacar que en 2019 houbo un novo incremento na creación de ICCE (Figura 6), como o GdC Orro en Culleredo, Xirimolo do Casino en Carballo ou, o máis recente, O Zuleiro en Antas de Ulla.

Figura 6. Cronografía dos anos fundacionais das iniciativas analizadas.

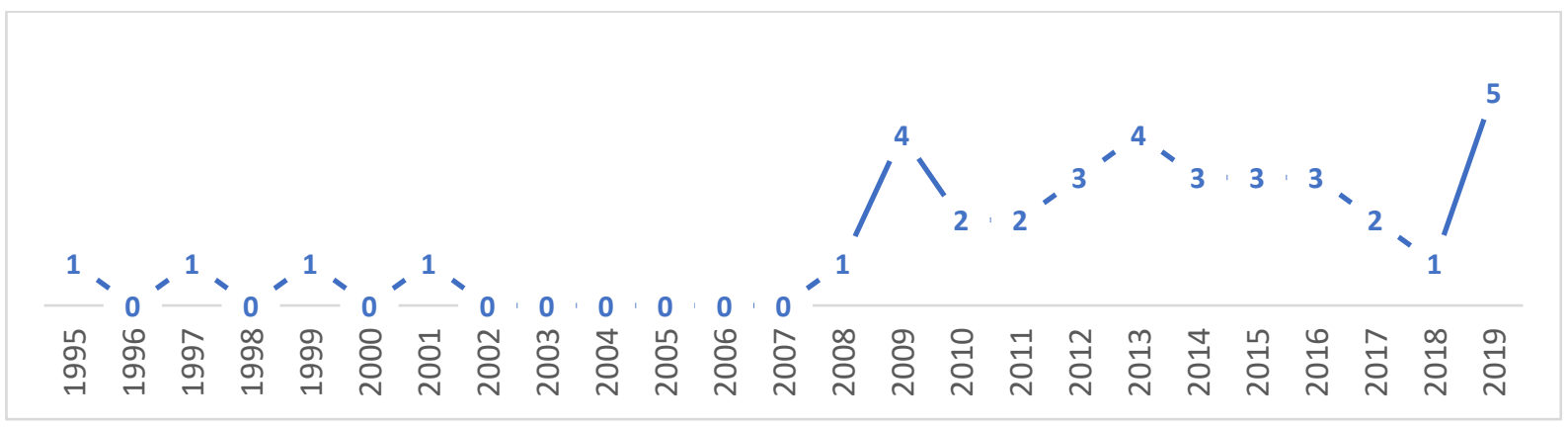

Elaboración propia.

En canto á figura xurídica das iniciativas analizadas, salientar que os GdC son o único modelo de iniciativa no que hai colectivos non constituídos en ningunha figura xurídica -en trece casos-, se ben os oito casos restantes están rexistrados como asociacións. Así mesmo, a Rede de Produción e Consumo O Careón é tamén unha asociación, do mesmo xeito que as sete iniciativas que desenvolven mercados autoxestionados. Pola súa banda, tanto as catro cooperativas de consumo como as iniciativas de comercialización adoptan o modelo da cooperativa -sexa de consumo ou de traballo asociado-, principalmente baixo a figura de sociedade cooperativa galega (SCG), coa lóxica excepción da ONG-D Amarante-Setem.

Con relación ás motivacións que orixinaron as iniciativas, de entre as opcións posibles nunha escala Likert-5 sobre a súa relevancia, no agregado sobresae acceder a produtos de confianza $(\bar{X}=4,70)$, adoptar un modo de vida ambientalmente máis responsable $(\bar{X}=4,62)$,

\footnotetext{
${ }^{12}$ Non foi ata 2010 que se constituíu como cooperativa (Nota: tras a finalización do presente traballo, recibiuse a nova da clausura desta iniciativa decana no consumo ecolóxico en Galicia).

${ }^{13}$ Aínda que non se formalizaría ata 2001.
} 

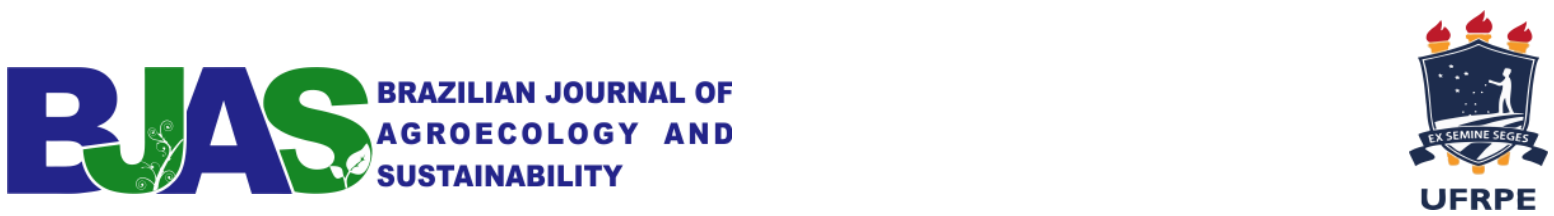

procurar unha alimentación máis saudable e promover un modelo de alimentación máis xusto (ambas con $\bar{X}=4,59$ ). Por contra, as motivacións con menores índices de relevancia foron dispoñer dunha fonte de ingresos económicos $(\bar{X}=2,22)$, imitar ou replicar unha iniciativa similar $(\bar{X}=2,68)$ e reducir o gasto en alimentación $(\bar{X}=2,78)$. Cómpre salientar que entre as cooperativas de consumo hai un consenso absoluto en asignar a maior relevancia $(\bar{X}=5)$ a acadar maior autonomía para decidir que producir ou consumir, motivación vinculada ao concepto de soberanía alimentaria ${ }^{14}$. En cambio, nas iniciativas de comercialización este consenso ten lugar arredor de adoptar un modo de vida ambientalmente máis responsable, promover modelos alternativos de relación económica e promover un modelo de alimentación máis xusto, estas dúas últimas de orientación socioeconómica. Neste sentido, ditas iniciativas presentan, xunto cos mercados autoxestionados, unha maior valoración da motivación dispoñer dunha fonte de ingresos económicos $(\overline{\mathrm{X}}=4)$, que obtén loxicamente unha puntuación especialmente baixa entre os $\operatorname{GdC}(\bar{X}=1,19)$. Ao demandar que se destaque a motivación máis importante de todas, a máis frecuente é a de acadar maior autonomía para decidir que producir ou consumir (n=9), seguida de adoptar un modo de vida ambientalmente máis responsable $(n=8)$ e promover un modelo de alimentación máis xusto $(n=5)$, todas elas cun claro carácter ético e relacionadas con nocións vinculadas á agroecoloxía política ${ }^{15}$, como a soberanía alimentaria, a sustentabilidade ambiental ou a xustiza social.

No referido á composición das iniciativas, sempre en base ás cantidades aproximadas reportadas polas persoas entrevistadas sobre cada unha delas ${ }^{16}$, compútanse un total de 1378 participantes no conxunto das iniciativas, das cales o 63\% son mulleres. Esta proporción é lixeiramente superior nos $\mathrm{GdC}$ (65\% de mulleres) que nas cooperativas de consumo (58\%), sendo especialmente notable nas iniciativas de comercialización $(71 \%)$ e representando a rede

\footnotetext{
${ }^{14}$ Segundo se estableceu na Declaración de Nyéléni emanada do Foro Mundial sobre Soberanía Alimentaria (FMSA) celebrado o ano 2007 en Sélingué (Malí), a "soberanía alimentaria é o dereito dos pobos a alimentos nutritivos e culturalmente adecuados, accesibles, producidos de forma sostible e ecolóxica, e o seu dereito a decidir o seu propio sistema alimentario e produtivo" (FMSA, 2007, p. 1).

15 Para Calle, Gallar e Candón (2013) a agroecoloxía política ocúpase "de entender e acompañar a emerxencia de expresións de economía social que reproducen bens ambientais e bens cooperativos no conxunto do sistema agroalimentario, por oposición ás economías depredadoras, como é o caso do capitalismo" (p. 250- 251). É dicir, atende aos "procesos de cooperación social que constrúen estilos alimentarios (pautas e redes de produción, distribución, consumo) equitativos e sustentables: a democratización alimentaria en definitiva" (p. 251). Deste xeito, engloba "enfoques de cambio social, dende o persoal e micro ata o institucional e macro, que reflexionan sobre condicións ou modelos para unha transición agroecolóxica" (p. 246).

${ }^{16}$ Hai que ter en conta que en moitos casos as cifras están baseadas en estimacións das persoas entrevistadas, xa que non contan cun rexistro exacto do número de participantes do momento no que se realiza a entrevista, ou ben computan familias ou unidades de consumo no canto de persoas que participan dun xeito máis directo -sucede especialmente entre os GdC non constituídos como asociación-.
} 

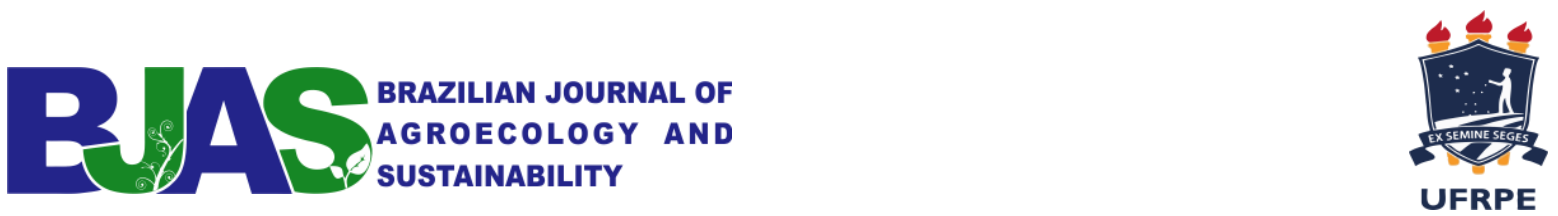

de produción e consumo analizada o único modelo no que as mulleres son minoría (48\%). O número de participantes por iniciativa varía moito en función do modelo, sendo as de maior tamaño as cooperativas de consumo, destacando o caso de Árbore, que contaba na data da entrevista con 334 socios. Os GdC presentan unha dimensión menor, que varía entre 8 e 22 unidades de consumo. Sobresae o caso de Tarabela, con 60 asociados, se ben o número dos que realmente participan no GdC é moito menor. Unha dimensión similar aos GdC presentan os colectivos que desenvolven mercados autoxestionados, cunha media de 19 persoas, cunha grande disparidade entre as 10 que desenvolven as feiras labregas organizadas polos Foros Ecolóxicos da Barbanza ${ }^{17}$ ou as 11 do Mercado de Alimento Labrego e as 50 que o fan en $\mathrm{O}$ Toxo, se ben esta é unha asociación constituída tanto por produtoras/es como por consumidoras/es que forman parte da iniciativa como socias/os colaboradoras/es. Na única rede de produción e consumo identificada participan 29 persoas, mentres que as agrupadas como iniciativas de comercialización presentan cifras moi dispares: das/os 70 socias/os de Amarante Setem ás tres socias que conforman respectivamente as CTA Bico de Grao e o Mercado da Terra de Ferrol. Rexusto, aínda que ten un modelo de xestión moi particular asumido por unha única persoa, presenta cifras similares ás dos $\mathrm{GdC}$ (18 persoas, entre produtoras/es e consumidoras/es implicadas/os).

O grao de implicación das/os participantes das distintas iniciativas é moi variable. En función dos modelos analizados, as cooperativas de consumo presentan niveis de implicación moi baixos, sen exceder en ningún caso o $36 \%$, en contraste cos mercados autoxestionados, nos que, salvo en tres casos, todas as persoas que forman parte da iniciativa participan de maneira activa no seu funcionamento, destacando en sentido contrario o caso de O Toxo, que implica activamente só ao 14\% -esencialmente as/os produtoras/es-, posto que as/os socias/os colaboradoras/es contribúen unicamente mediante o pagamento de cotas e consumindo no mercado. Dos GdC, só cinco presentan índices de implicación superiores ao 80\%, sobresaíndo tres casos -A Morangueira, Des Pensa e Semente- no que a participación é total, xa que é preceptiva, fundamentalmente a través de equipos, comisións de traballo ou reparto e rotación de tarefas. Por contra, dez GdC amosan taxas participación inferiores ao 50\%. Entre as iniciativas de comercialización atopamos unha grande disparidade, que vai da implicación total

\footnotetext{
${ }^{17}$ Número seguramente maior de sumar todas as persoas que conforman en conxunto os Foros Ecolóxicos da Barbanza e Sachos á Rúa, asociación que en última instancia impulsa e da cobertura xurídica a esta iniciativa. En calquera caso, sempre resulta complicado comparar cifras no número de participantes entre experiencias con distintos modelos de funcionamento e articulación.
} 

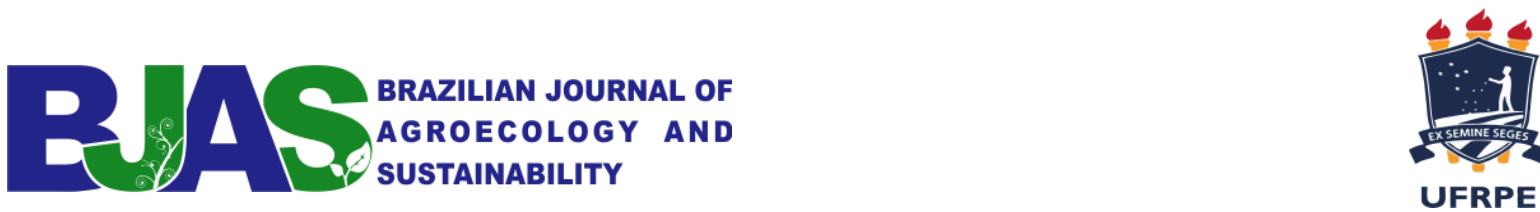

das tres socias da CTA Bico de Grao, ata o caso de Rexusto, onde a súa impulsora é a única persoa que se encarga de todo o seu funcionamento.

En canto á loxística e os espazos de consumo, todos os GdC funcionan con sistemas de reparto colectivo, sexa en locais alugados ( 5 casos, 3 deles compartidos con outras entidades), espazos cedidos por entidades sociais (4) ou pola administración local (2), ou en domicilios dos membros da iniciativa (4) e locais particulares destes (3) (Figura 1). A rede de produción e consumo opta por esta última opción para facer o reparto de pedidos externos, mais tamén ten outras canles e espazos de distribución adaptados ás circunstancias dos seus integrantes. Tanto as cooperativas de consumo como as iniciativas de comercialización dispoñen de local comercial -se ben no caso de Zocamiñoca é só para socias/os-, coa única excepción de Rexusto, que basea o seu funcionamento no reparto a domicilio e a disposición de puntos de recollida. Algunhas destas iniciativas contan ademais con sistemas de reparto de cestas pechadas -Bico de Grao, por exemplo, así como reparto a domicilio e en bicicleta empregado por Zocamiñoca e Panxea. Os mercados autoxestionados adoitan ser ao aire libre, salvo o de Labrega Natura, que ten lugar no interior do mercado de San Agustín da Coruña, e o Mercado da Terra, no mercado municipal Quiroga Ballesteros de Lugo (Figura 7).

Figura 7. Mercados autoxestionados no interior de mercados de abastos.

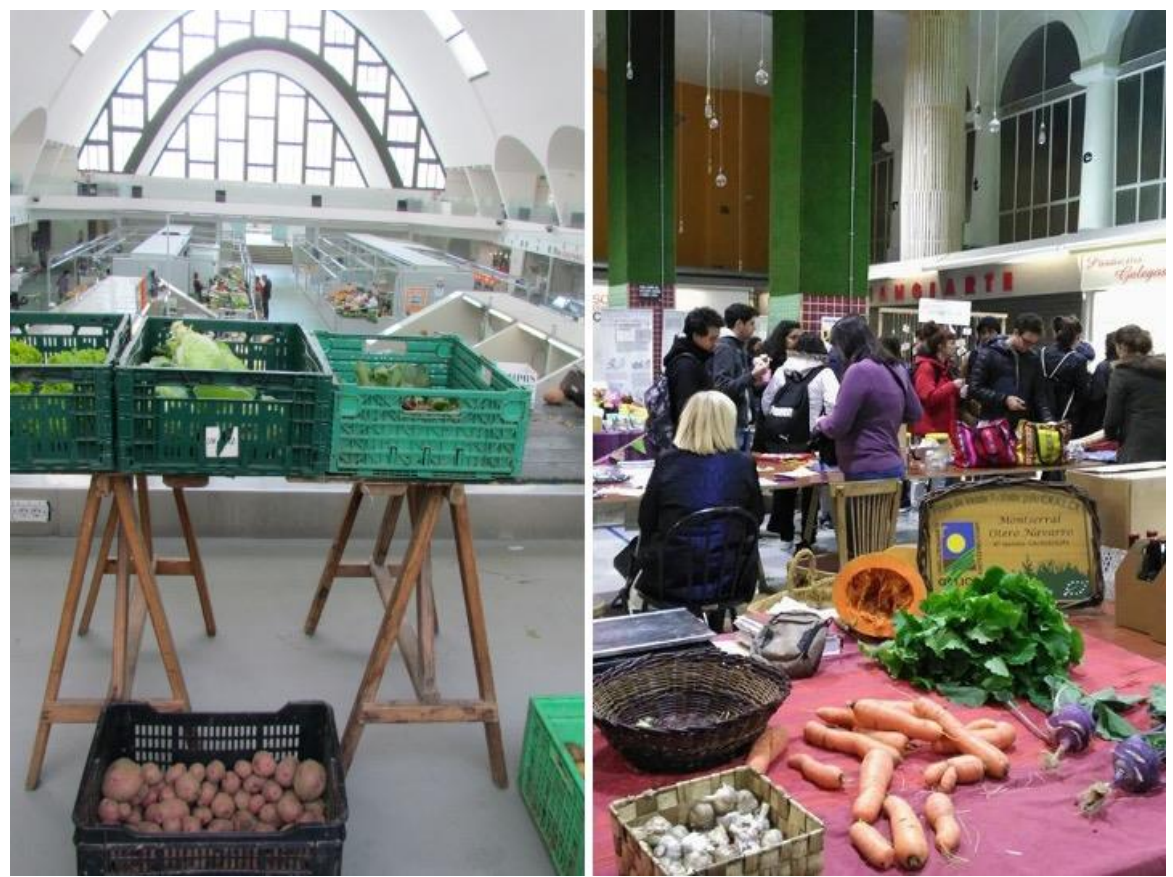

Esquerda: Mercado autoxestionado de produtoras/es locais organizado por Labrega Natura no interior do mercado de San Agustín (A Coruña); fotografía: K.M. Bisquert (2019). Dereita: Mercado da Terra, celebrado no interior do mercado municipal Quiroga Ballesteros (Lugo); fotografía: https://mercadodaterra.noblogs.org. 

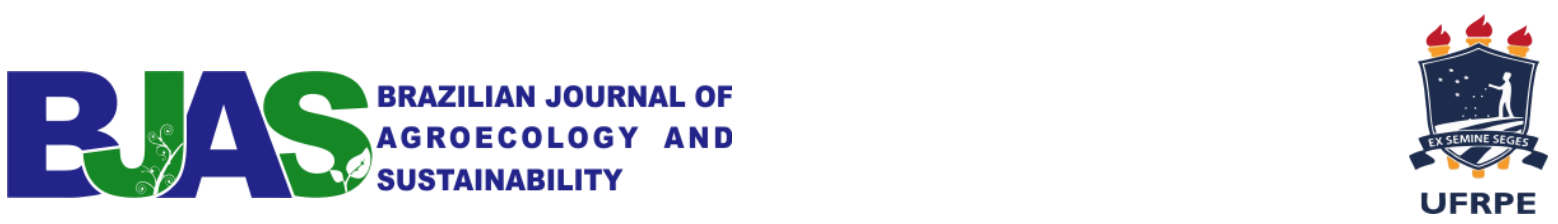

No que respecta á gobernanza, os órganos de xestión e a toma de decisións, predomina a asemblea e a busca do consenso, especialmente entre os $\mathrm{GdC}$, a rede de produción e consumo e os mercados autoxestionados, se ben algúns GdC (11 casos) e mercados (3) tamén contan ou contaron con equipos, comisións, grupos de traballo ou liderados de carácter orgánico para as decisións máis operativas, temas concretos, tarefas loxísticas, de xestión, pedidos, etc., nalgún caso con carácter preceptivo, noutros conformados de xeito voluntario polas/os participantes máis activas/os. Tres iniciativas din facer uso de aplicacións de mensaxería dixital para tomar decisións, unha delas -GdC Vedra- como única vía de xestión da iniciativa, alén de xuntanzas informais. É particular o caso de Eco_Lóxico, que conta cunha eco-equipa, conformada por tres socias/os máis a persoa contratada para a xestión do GdC. Sete GdC e catro mercados din recorrer á votación de maneira complementaria á busca de consenso. Catro GdC constituídos como asociacións sinalan contar cunha xunta directiva, nun dos casos de carácter rotativo -cada dous anos-, outro só a nivel formal, e outro porque a asociación abarca máis do que é estritamente o GdC. Pola súa banda, todas as cooperativas contan con asemblea e consello reitor, que actúa como órgano representativo e de toma delegada das decisións máis técnicas ou executivas. Tres delas tamén contan con comisións ou grupos de traballo e inclúen a busca de consenso e a votación nos seus procedementos de toma de decisións. No caso de Árbore, destácase a función do socio-traballador na xestión da tenda; Panxea celebra reunións mensuais abertas para tratar o devir do proxecto; en Zocamiñoca a coordinadora é un espazo aberto aos socios que queiran participar e o zoquelarre é unha asemblea aberta máis frecuente; Aldea Integral destaca o modelo autoxestionado da súa horta. Por último, nas CTA a toma de decisións recae nas socias da cooperativa, Amarante Setem ten xunta directiva para planificar e tratar os asuntos máis técnicos, grupos de traballo para as decisións máis áxiles e asembleas para ratificar decisións e manter debates transversais. Rexusto é a única iniciativa con dirección unipersoal.

\subsection{Dimensión socioeducativa}

Entre as principais actividades socioeducativas das iniciativas, sobresae a organización ou participación en charlas e conferencias sobre unha ampla diversidade de asuntos principalmente presentando a iniciativa ou outros proxectos, participando en mesas redondas ou abordando temas de consumo responsable, agricultura ecolóxica ou soberanía alimentaria, entre outros-, así como a organización ou participación en eventos temáticos, como poden ser mercados e feiras puntuais, celebracións e actividades lúdicas ou xornadas temáticas e de portas abertas (29 casos en ambos tipos). A estas síguelle a edición de materiais impresos -carteis de 

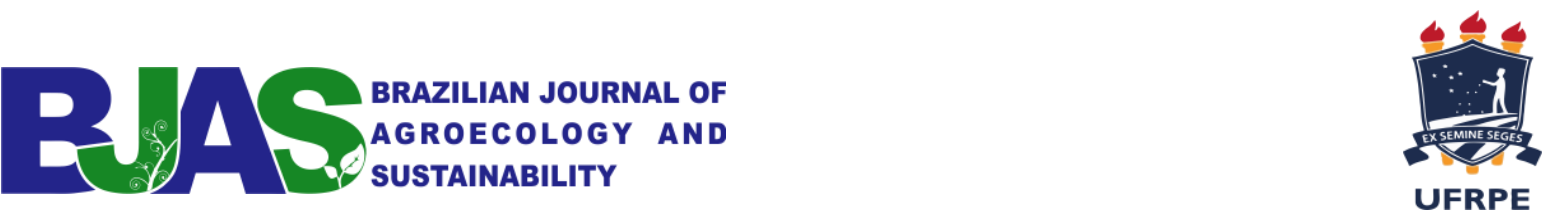

difusión das actividades e folletos informativos- e a organización de cursos ou obradoiros prácticos, con 25 casos respectivamente. Outras actividades recorrentes son as de sensibilización ( 23 casos) e a difusión de información por redes sociais (22 casos).

A nivel temático, as actividades xiran principalmente arredor do consumo -responsable, ecolóxico, local, consciente (22 casos); alimentación, nutrición e saúde (12 casos); modelos alternativos -socioeconómicos, agroalimentarios, de consumo (10 casos); acción colectiva e comunidade (9 casos); ecoloxía e responsabilidade ambiental (8 casos); agroecoloxía e condicións socio-laborais do sector primario (6 casos en ambos temas); cambios individuais de hábitos, de conciencia e apoio á produción e á economía local (5 casos respectivamente); e visibilización de proxectos e produtos (4 casos). Os obxectivos prioritarios con relación ao desenvolvemento destas actividades son, nesta orde: visibilizar as alternativas ao sistema agroalimentario dominante, concienciar sobre as implicacións do actual modelo agroalimentario e modificar hábitos de consumo. Neste sentido, non se detectan diferencias salientables entre os distintos modelos de ICCE analizados.

Entre as dificultades á hora de desenvolver accións socioeducativas, identifícanse tanto de carácter endóxeno como esóxeno. Entre as dificultades endóxenas, destaca a carencia de recursos -económicos, de espazo para as actividades (15 casos), de tempo (14), de implicación das integrantes da iniciativa (13), de carácter organizativo (13) e de situación vital das participantes -multimilitancia, cargas laborais e familiares, dispersión xeográfica (9). Entre as dificultades esóxenas, sobresaen as administrativas (9 casos), a escasa resposta do público destinatario das actividades (7) e barreiras de carácter cultural entre a cidadanía (7).

\subsection{Cara novas formas e canles de consumo e participación}

Tras esta aproximación ás ICCE en Galicia, pódese concluír que na últimas décadas houbo un incremento considerable no número de iniciativas, acompañada dunha diversificación e transformación dos modelos máis clásicos -as cooperativas e as asociacións de consumo- cara outros máis adaptados ás circunstancias das persoas que as compoñen e impulsan, destacando GdC con distintos modelos de xestión, redes de produción e consumo e mercados autoxestionados. Nesta evolución percíbese unha tendencia xeral cara modelos menos esixentes na implicación por parte das/os consumidoras/os, de menor dimensión e máis localizados, pero que abren a participación neste tipo de iniciativas a un maior número e perfil de persoas. Porén, 

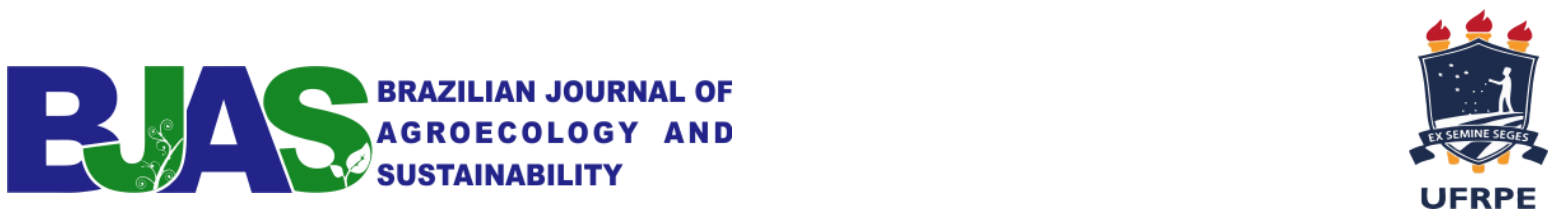

tamén aparecen casos en sentido oposto no eido da implicación, con iniciativas que asumen un modelo de ASC, como son Semente e Xurumelxs.

En canto á dimensión socioeducativa das ICCE, identificouse unha gran cantidade e diversidade de propostas, dun gran potencial para trasladar á cidadanía valores e prácticas do consumo ecolóxico colectivo, e que xunto á súa propia experiencia poden constituír unha base excepcional para deseñar programas socioeducativos para a promoción da cultura da sustentabilidade. Así mesmo, salvo algunha excepción que cuestiona lexitimamente se as ICCE deben asumir unha función socioeducativa, a maior parte teñen esta dimensión moi desenvolvida e integrada como práctica habitual ligada á súa vocación transformadora.

En suma, podemos concluír que as ICCE son actualmente unha realidade emerxente en Galicia, pois se ben a súa traxectoria no territorio galego xa é dilatada, a relativamente recente expansión no número de iniciativas, diversificación de modelos e dispersión xeográfica, apuntan cara unha crecente relevancia social. Así mesmo, se ben actualmente aínda constitúen innovacións sociais anecdóticas fronte á hexemonía na distribución alimentaria das grandes superficies de comercialización -nomeadamente os supermercados-, as ICCE seguen a construír e consolidar canais curtas de comercialización e redes de cooperación más ou menos estreitas e estables entre elas. Deste xeito, tanto a través da súa actividade habitual e a súa presencia no espazo público como do desenvolvemento de actividades socioeducativas, deveñen cada vez máis en axentes colectivos de especial relevancia á hora de promover unha cultura agroalimentaria alternativa e modelos de dieta acordes coa cultura da sustentabilidade que acompasen á cada vez máis urxente transición agroecolóxica dos sistemas agroalimentarios.

\section{REFERENCIAS}

Bisquert, K. M., \& Meira, P. Á. (2019). Validação de instrumento de recolhimento de dados para uma aproximação desde a educação ambiental ao movimento social agroecológico na Galiza e sua dimensão socioeducativa. Ambiente \& Educação, 24(2), 236-266. Recuperado de https://doi.org/10.14295/ambeduc.v24i2.9731_[Revisado o 9 de xullo de 2020].

Couceiro, A., Martínez, Y., Alonso, J., Santafé, E., Saralegui, P., \& Ortega, E. (2016). Grupos de consumo:Una cultura agroalimentaria sostenible. Madrid: Libros en Acción.

Consello Regulador de Agricultura Ecolóxic de Galicia (2017). Barómetro 2017. Percepción e consumo de alimentos ecolóxicos en Galicia. Monforte de Lemos: CRAEGA. Recuperado de https://www.craega.es/wp-content/uploads/2019/03/Barometro-2017.pdf [Revisado o 9 de xullo de 2020]. 
Esteve-Llorens, X., Martín-Gamboa, M., Iribarren, D., Moreira, M. T., Feijoo, G., \& GonzálezGarcía, S. (2020, Jan.). Efficiency assessment of diets in the Spanish regions: A multicriteria cross-cutting approach. Journal of Cleaner Production, 242, 118491. Recuperado de https://doi.org/10.1016/j.jclepro.2019.118491 [Revisado o 9 de xullo de 2020].

Esteve-Llorens, X., Moreira, M. T., Feijoo, G., \& González-García, S. (2019). Linking environmental sustainability and nutritional quality of the Atlantic diet recommendations and real consumption habits in Galicia (NW Spain). Science of The Total Environment, 683, 71-79. Recuperado de https://doi.org/10.1016/j.scitotenv.2019.05.200 [Revisado o 9 de xullo de 2020].

Herrero, Y., Cembranos, F., \& Pascual, M. (Coords.) (2011). Cambiar las gafas para mirar el mundo: Una nueva cultura de la sostenibilidad. Madrid: Libros en Acción.

Lema-Blanco, I., García-Mira, R., \& Muñoz-Cantero, J. M. (2015). Las iniciativas de consumo responsable como espacios de innovación comunitaria y aprendizaje social. Revista de Estudios e Investigación en Psicología y Educación, (14), 29-33. Recuperado de https://doi.org/10.17979/reipe.2015.0.14.316 [Revisado o 9 de xullo de 2020].

Meybeck, A., \& Gitz, V. (2017). Sustainable diets within sustainable food systems. Proceedings of the Nutrition Society, 76(1), 1-11. Recuperado de https://doi.org/10.1017/S0029665116000653 [Revisado o 9 de xullo de 2020].

Rodríguez, R. R. (2014). Os circuitos curtos de comércio de alimentos na Galiza atual: Na procura de alternativas ao oligopólio da distribuiçom (ICEDE Working Paper Series, 10). Santiago de Compostela: Universidade de Santiago de Compostela. Recuperado de https://www.usc.es/export9/sites/webinstitucional/gl/investigacion/grupos/icede/descarga s/WP_Os_circuitos_curtos_Rios.pdf [Revisado o 9 de xullo de 2020].

Simón, X., Copena, D., \& Rodríguez, L. (2010). Construyendo alternativas agroecológicas al sistema agroealimentario global: acción y reacción en el Estado español. Revista de Economía Crítica, 10, 138-175. Recuperado de http://revistaeconomiacritica.org/sites/default/files/7.pdf [Revisado o 9 de xullo de 2020].

Soares, R. O., Tavares, P., Lu, M., Cristóvão, A., Fra, M. P., \& Arias, A. I. G. (2020). A dinâmica de comercialização em circuito curto em Lugo_Galiza. Revista de Ciências Agrárias, 43(spe1), 26-35. Recuperado de https://doi.org/10.19084/rca.19029 [Revisado o 9 de xullo de 2020].

Vázquez, M. D. (2017). Funcionamiento y Evolución de una asociación de consumidores/as “O Bandullo Ecolóxico". AE. Revista Agroecológica de Divulgación, (28), 28-29. 
